\title{
A ciência a serviço da saúde humana e ambiental: entrevista com o químico, geneticista e ambientalista Flávio Lewgoy
}

\section{Science in the service of human and environmental health: interview with chemist, geneticist, and environmentalist Flávio Lewgoy}

Entrevista com

Flávio Lewgoy

in memoriam

Concedida a

Elenita Malta Pereira

Professora, Departamento de História/Universidade Estadual do Centro-Oeste.

Rua Padre Salvador, 875

85015-430 - Santa Cruz -

Guarapuava - PR - Brasil

elenitamalta@gmail.com
PEREIRA, Elenita Malta. A ciência a serviço da saúde humana e ambiental: entrevista com o químico, geneticista e ambientalista Flávio Lewgoy. História, Ciências, Saúde - Manguinhos, Rio de Janeiro, v.24, n.1, jan.-mar. 2017, p.261-269.

Resumo

Entrevista com o químico e geneticista Flávio Lewgoy, que também foi perito criminalístico e ambientalista. Lewgoy protagonizou importantes lutas pela saúde humana e pela qualidade ambiental no Rio Grande do Sul. Foi um dos responsáveis pela redação das leis estadual (1982) e federal (1989) dos agrotóxicos. Ele acreditava possuir o dever de usar os conhecimentos científicos para sustentar suas posições na militância ambiental e percebia esta atuação como um compromisso ético, uma retribuição à sociedade, por sua formação, realizada em instituições públicas.

Palavras-chave: Flávio Lewgoy (1926-2015); militância ambiental; ética na ciência; luta contra os agrotóxicos.

Abstract

Interview with chemist and geneticist Flávio Lewgoy, who was also an expert criminal and environmental investigator. Lewgoy was at the center of important struggles for human health and environmental quality in Rio Grande do Sul, and was one of the people behind state (1982) and federal (1989) laws governing pesticide use. He believed he had a duty to use scientific knowledge to support his positions on environmental activism and saw this activity as an ethical commitment, a way of paying back society for the education he received in public institutions.

Keywords: Flávio Lewgoy (1926-2015); environmental activism; ethics in science; fight against pesticides. 
Procurei devolver o que me deram, o que o povo pagou para eu estudar.

Não fiz mais do que a minha obrigação. Além do mais, eu gostava de fazer, ainda gosto. Se não tivessem me pagado, eu pagava para fazer (risos).

Flávio Lewgoy, 26 set. 2014.

Nascido em Porto Alegre, Flávio Lewgoy (1926-2015) graduou-se em química industrial pela Universidade Federal do Rio Grande do Sul (UFRGS) em 1948, onde foi professor de 1959 a 1992. Entre 1959 e 1960, cursou especialização em genética na Universidade do Texas, em Austin, nos EUA, como bolsista da Fundação Rockefeller (Belmonte, set. 2010). Foi professor titular de química e pesquisador na área de genética na UFRGS, e ali fundou a disciplina de ecogenética, em 1990. Ele também foi responsável pelo laboratório do Instituto de Criminalística do Rio Grande do Sul e pioneiro na introdução da química forense no estado. Desvendou inúmeros crimes a partir da análise de vestígios de substâncias químicas.

Como ambientalista, Lewgoy envolveu-se em diversas lutas. Tornou-se membro da Associação Gaúcha de Proteção ao Ambiente Natural (Agapan) em 1974, entidade a partir da qual construiu uma militância ambiental durante 41 anos. A Agapan foi fundada em 27 de abril de 1971, em meio ao período mais repressivo do regime militar. Entre as principais reivindicações, constava já em seu "Programa de luta" (Agapan, 1971) a defesa "da natureza ameaçada, nas formas de fauna, vegetação, solo, atmosfera, águas"; a "promoção da ecologia como ciência da sobrevivência"; a luta "por uma nova moral ecológica". Além disso, a Agapan conclamava seus membros a realizar

\begin{abstract}
o combate ao massacre de animais e à caça indiscriminada, às devastações das vegetações e às queimadas, ao uso exagerado dos meios mecânicos contra o solo e a toda erosão provocada ou facilitada, à poluição do ar causada pelas indústrias e veículos, à poluição dos cursos d'água pelos resíduos industriais e esgotos não tratados, ao uso indiscriminado de inseticidas, fungicidas, herbicidas, raios ionizantes, às destruições desnecessárias de belezas paisagísticas (Pereira, 2011, p.131).
\end{abstract}

A Agapan foi a primeira entidade ambientalista brasileira, indo além de propostas conservacionistas anteriores, defendidas por entidades como a Associação de Defesa da Flora e da Fauna (Adeflora), criada em 1956, em São Paulo, e a Fundação Brasileira para a Conservação da Natureza (FBCN), fundada em 1958, no Rio de Janeiro. No Rio Grande do Sul, houve também a União Protetora da Natureza (UPN), que atuou entre 1955 e 1963 sob a liderança de Henrique Luiz Roessler, conjugando preservacionismo e conservacionismo.

Entre o grupo de fundadores da Agapan, havia professores de biologia da UFRGS e da Universidade do Vale do Rio dos Sinos (Unisinos), jornalistas, advogados, engenheirosagrônomos e antigos membros da UPN de Roessler. Na primeira gestão da entidade, a presidência coube a José Lutzenberger (1926-2002), e a secretaria, a Augusto Carneiro (1922-2013).

Lutzenberger era engenheiro-agrônomo, havia trabalhado durante 13 anos para a multinacional Basf, atuando na Alemanha, na Venezuela e no Marrocos, entre outros países. Quando a empresa entrou no ramo dos agrotóxicos, no final dos anos 1960, uma crise de 
consciência o levou a uma virada na trajetória: voltou para o Brasil e tornou-se ambientalista, atuando justamente como um dos primeiros e principais combatentes do uso de agrotóxicos no Brasil. Atuou em defesa da agricultura orgânica, da Floresta Amazônica e em inúmeras lutas ambientais. Ocupou o cargo de secretário de Meio Ambiente durante o governo Collor (1990-1992) e recebeu diversos prêmios internacionais em reconhecimento por sua luta pela natureza. Foi presidente da Agapan de 1971 a 1983.

Augusto Carneiro foi um dos mais importantes fundadores da Agapan. Entre o final de 1970 e o começo de 1971, entrou em contato com possíveis interessados em fundar uma associação ambientalista em Porto Alegre, principalmente os ex-sócios da UPN de Henrique Roessler e professores universitários. Ocupou os cargos de secretário e tesoureiro da Agapan entre 1971 e 1984, quando se afastou da entidade.

O escopo de variadas lutas em que a Agapan envolveu-se atraiu a atenção de Lewgoy, em especial o questionamento da poluição provocada pela sociedade industrial, ponto relacionado às suas pesquisas em química. Ele foi um dos críticos à Celulose Borregaard, instalada na cidade de Guaíba, às margens do lago de mesmo nome, de onde exalava um cheiro de ovo podre que se alastrava por toda a Porto Alegre até a região metropolitana. Uma campanha que envolveu políticos, jornalistas e ambientalistas levou ao fechamento da fábrica por cem dias entre 1973 e 1974 (Pereira, 2014). A empresa mudou de donos e de nome várias vezes (entre eles, o mais lembrado até hoje é "Riocell"), mas Lewgoy se manteve como um de seus principais opositores até o fim da vida. ${ }^{1}$ Foi ele quem embasou a crítica da Agapan à duplicação da fábrica, em 1992, e à quadruplicação, entre 2013 e 2015. O principal argumento era a possível contaminação das águas do lago Guaíba pelos efluentes da fábrica, que poderiam conter as dioxinas, partículas organocloradas que se formariam em decorrência do uso de cloro no branqueamento da celulose.

Lewgoy também foi um dos protagonistas da luta contra os agrotóxicos no Rio Grande do Sul. Desde o início de sua fundação, a Agapan promoveu importantes debates sobre os danos ambientais e à saúde humana provocados pelo uso dos pesticidas. Em 1981, Lewgoy foi um dos principais articuladores da CPI Estadual dos Agrotóxicos, que trouxe a público os problemas causados por esses produtos: uso além das quantidades recomendadas pelos agrônomos, intoxicação de agricultores (incluindo crianças) e animais, contaminação das águas do Guaíba, entre outros. A partir da publicação desses problemas na imprensa gaúcha, criou-se o ambiente propício, em 1982, para a aprovação da Lei Estadual dos Agrotóxicos (Rio Grande do Sul, 22 dez. 1982), cujo texto foi escrito com a ajuda de Lewgoy e de seus colegas ambientalistas. O professor da UFRGS também colaborou na redação da lei federal sobre o tema (Brasil, 11 jul. 1989).

Outra luta em que Lewgoy se envolveu foi a crítica aos organismos geneticamente modificados (OGMs), chegando a publicar artigo sobre sua posição em História, Ciências, Saúde - Manguinhos (Lewgoy, jul.-out. 2000). Naquele texto, ele identificou uma "acirrada controvérsia científica", que dividia os cientistas em dois grupos, "o grupo 'crítico', ou preocupado, em oposição à maioria 'triunfalista'”. Colocando-se no primeiro grupo, elencou

${ }^{1}$ Atualmente, a empresa se chama CMPC Celulose Rio-grandense. 
argumentos contrários à liberação dos transgênicos; entre eles, a limitação do conhecimento sobre o genoma humano, as possíveis falhas no processo de inserção de exogenes, as críticas aos registros desses produtos (muitos manifestavam graves falhas nos testes de toxicidade apresentados pelas empresas), o lobby das multinacionais junto aos órgãos de registro e regulamentação e os riscos ambientais envolvidos, como a contaminação de plantas não transgênicas pela deriva.

Entrevistei Lewgoy em 26 de setembro de 2014, em sua casa, no bairro Santa Cecília, em Porto Alegre. Fui encontrá-lo com o intuito de conversar sobre sua relação com José Lutzenberger, cuja trajetória foi meu objeto de estudo no doutorado. ${ }^{2}$ Entretanto, a entrevista foi muito além do tema previsto, felizmente, e Lewgoy falou de sua própria atuação como presidente da entidade (entre 1983 e 1987), as lutas em que se envolveu, especialmente contra os agrotóxicos, e a importância de sua formação como químico e geneticista na militância ambientalista.

Infelizmente, Lewgoy faleceu pouco mais de um ano após o nosso encontro, em 7 de novembro de 2015, vítima de um câncer. Estava com 89 anos, e, conforme o leitor poderá perceber na entrevista, em um balanço pessoal, entre vitórias e derrotas, parecia estar satisfeito com o que realizou na vida. Acreditava no compromisso ético e social do cientista. Em sua visão, aqueles que, como ele, haviam cursado o ensino médio e superior em instituições públicas tinham o dever de colocar seu conhecimento a serviço da sociedade, como forma de retribuição à educação recebida gratuitamente. Percebia sua atuação como militante ambientalista, por meio da qual utilizava seu conhecimento em química e genética em prol da saúde humana e do ambiente, como uma espécie de "pagamento" social dos estudos financiados "pelos impostos pagos pelo povo".

Eis, abaixo, a entrevista.

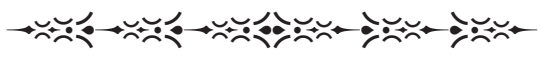

\section{Como foi sua entrada na Agapan e como conheceu José Lutzenberger?}

Sou químico, e meu objeto de pesquisa eram metais tóxicos, elementos de traços, que são elementos cuja concentração no organismo é inferior a 0,001\%, mas que apesar disso são muito importantes, inclusive porque têm também ação tóxica no meio ambiente, principalmente o carvão e produtos da combustão do carvão que, naquela época, como hoje, estavam em grande evidência. Interessei-me pelo tema, li alguns trabalhos sobre a composição do carvão e as emissões gasosas particuladas do carvão e vi que tinha muitos metais tóxicos nestas emissões. Era professor da UFRGS, e comecei a me dedicar ao assunto como matéria acadêmica, porque gostava da temática, como gosto até hoje. Aí começou a

\footnotetext{
${ }^{2}$ Desenvolvi tese sobre a militância e a produção intelectual de José Lutzenberger, no Programa de Pósgraduação em História da UFRGS. Meu foco foi a compreensão da ética ecológica por ele difundida ao longo de seus 31 anos como militante ambientalista. Para maior aprofundamento, ver Pereira (2016).
} 
surgir na imprensa a figura do Lutz [apelido de Lutzenberger] e a Agapan, que eram tratados como algo meio folclórico junto à discussão sobre ecologia. Notei que realmente o que eles diziam fazia sentido. Aos poucos, aproximei-me do Lutz, da Agapan, mas só fui me associar mesmo alguns anos depois da fundação, ou seja, não fui fundador. Tornei-me seu vice-presidente (1982-1983) e depois presidente (1983-1986).

No início, eu só me interessava por carvão e metais tóxicos. À medida que fui travando contato com o Lutzenberger e com a Agapan, fui ganhando maior atenção da mídia. Estávamos em plena ditadura militar, quando dar uma entrevista era uma situação de risco, mas por algum motivo os militares não viam os ecologistas como subversivos, embora efetivamente fôssemos, uma vez que odiávamos o sistema militar.

Entrei na Agapan e me tornei sócio por volta de 1974. Imediatamente fui nomeado conselheiro, e no começo dos anos 1980, vice-presidente. Como o Lutz viajava muito, eu estava sempre em exercício da presidência. Até que decidiram rever aquilo, pois todos os anos a assembleia de eleição renovava Lutzenberger como presidente e eu como vice. Um dia, a diretoria da Agapan em peso me cercou e me obrigou a aceitar a presidência, alegando que na prática eu já a exercia, em virtude da ausência constante do Lutz. Eles não saíram da minha casa enquanto eu não concordei.

Foi difícil para o senhor tomar a decisão de se candidatar a presidente?

Foi, mas ao final aceitei. Fiquei até concluir aquele mandato (1983) e acabei sendo reeleito (1984-1986). Mas o Lutz não encarou aquilo muito bem, achou que foi um golpe (risos). Até falou para um jornalista, que veio me interpelar: "Como vocês deram um golpe no Lutz?" Tive de explicar para ele.

O Augusto Carneiro ficou com essa impressão, de que foi um golpe...

O Carneiro foi basicamente o sustentáculo do Lutz: foi tesoureiro da Agapan, e todo o dinheiro arrecadado - a Agapan sempre foi pobre - era para pagar a secretária do Lutz, sobrava muito pouco. A Agapan não tinha recursos para coisas básicas, como editar um livro ou pagar funcionário, que nunca teve. Até hoje, tudo lá é voluntário. Tampouco teve uma sede, vivia se mudando. Quando alguém cedia uma sede, tempo depois era reclamada e tinha de mudar.

Depois da sua eleição, o Lutz não voltou mais para a Agapan...

O Lutz ficou bastante chateado. De certa forma, procurei compensar aquilo propondo numa assembleia que ele fosse declarado presidente de honra, inclusive defendendo que fosse o primeiro e último da entidade. Mais tarde, propuseram que eu fosse presidente de honra, contrariando minha indicação, então eu disse: "Avisei que a Agapan só ia ter um presidente de honra" (risos).

\section{Como foi ser presidente da Agapan?}

Foi tremendo. Naquela época, a Agapan era apenas uma organização não governamental. A primeira entidade realmente ecologista do Brasil, porque, até então, o que havia eram entidades conservacionistas, o que é bem diferente das ecologistas. 
Qual a diferença entre ecologista e conservacionista?

Se olhares a história do Brasil, o primeiro conservacionista foi José Bonifácio de Andrada e Silva. Ele defendeu as florestas, era contra o desflorestamento. Vamos além disso, pois, além de sermos conservacionistas, consideramos importante a preservação da flora e da fauna (o meio ambiente é isso, flora e fauna - o nosso Pampa está sendo aos poucos devastado, como a própria Mata Atlântica). O conservacionismo é importante, mas não basta por si só, é preciso uma atitude mais combativa, de cunho político. Como o próprio Lutz dizia, a Agapan é apartidária, mas não é apolítica. Ela é uma entidade política, pois atua politicamente.

\section{O senhor foi professor por muitos anos?}

Fui, mas não quis continuar dando aula após a aposentadoria, como muitos. Preferi me dedicar à questão ambiental.

Nos anos 1970 havia alguma repressão da ditadura às atividades da Agapan?

Sim. Havia um espião permanente nas reuniões da Agapan, um tal de Hércules. Ele tinha uma expressão séria, entrava calado e saía mudo. O pessoal gozava da cara dele, todo mundo sabia quem ele era. Ele só ficava lá parado, escutando, vendo se saía alguma coisa contra o regime. Às vezes dizíamos umas barbaridades, só para gozar da cara dele (risos).

\section{Então ele nunca fez uma denúncia de vocês?}

Não, nunca, porque os militares não acreditavam que fôssemos "subversivos", eles não ligavam. Eu, aliás, fazia críticas a ações governamentais, saía no jornal, mas não me acontecia nada (risos). O SNI mandou a gente prestar depoimento na UFRGS. Uma vez mandaram uma moça, que se fingiu de jornalista. Ela queria saber o que fazia a Agapan. Eu disse: "A Agapan parece que tem grande poder, mas isso é um mito, somos apenas uma entidade ecologista". Aí ela disse: "O senhor me ajudou muito". E eu: "Ah, imagino" (risos).

\section{Como foi a campanha contra os agrotóxicos nos anos 1970?}

Essa sim foi memorável. Dei várias entrevistas naquela época. Como não havia muitos dispostos a falar na época da ditadura militar, eu era muito procurado, o telefone não parava. Eu não tinha medo de falar, porque mesmo que procurassem, não iam encontrar nenhuma associação minha; embora eu fosse esquerdista, nunca fui membro do partido comunista. Teve quem me denunciou como comunista, mas nunca encontraram provas disso. E como eu trabalhava na polícia, era perito criminalístico, aí era difícil.

A lei dos agrotóxicos [estadual] teve impulso na época da ditadura. O secretário de Saúde, Germano Bonow, deu-nos uma grande ajuda: quando foi divulgada a presença de agrotóxicos na água do Guaíba, houve quem considerasse inconstitucional esse tipo de declaração, mas ele contrapôs: "Inconstitucional é ter agrotóxicos na água, contaminando a água potável do Guaíba". Conseguimos a aprovação da lei dos agrotóxicos, que depois inspirou muitos estados brasileiros a fazer leis similares, e teve repercussão internacional, porque as multinacionais, descontentes, fizeram protestos, dizendo que havia interferência no comércio internacional. Mas a lei passou. 
Mas as indústrias agroquímicas queriam vender, não é?

Queriam, como querem até hoje, infelizmente, apesar da lei nacional dos agrotóxicos, que também ajudei a formular. Passei uma semana em Brasília. Colaborei na aprovação da lei, porque fui falar com cada um dos integrantes da comissão responsável. Havia, por exemplo, representantes dos fabricantes de produtos veterinários, que tinham medo que a lei fosse afetá-los. Convenci-os a votar conosco, justificando que a lei não era propriamente contra os produtos veterinários. Também tinha um representante dos fazendeiros do Pantanal, que não sabia bem do assunto, e a quem também expliquei que a lei não os afetaria. Dessa forma, conquistamos maioria na comissão e aprovamos a lei nacional dos agrotóxicos. Essa é uma das coisas de que eu gosto de me lembrar, da qual eu penso que, afinal, minha vida não passou em vão.

Já são mais de 40 anos de luta. Nunca pensei em ser ecologista, o meu negócio era ser pesquisador. Tornei-me ecologista de repente. Lembro-me de conversar com o Lutz e de ele me dizer que todos os carros tinham obsolescência planejada. Claro que antes das obras do Lutz houve publicações importantes, ainda no fim da década de 1960, como a do Clube de Roma, ${ }^{3}$ com coisas válidas até hoje.

\section{Nunca houve conflito na universidade pelo fato de o senhor ser ecologista?}

Não, apenas me cobravam, às vezes, por aparecer muito [na imprensa]. Apesar disso, consegui que a universidade tolerasse minha atuação como ambientalista, sem que isso me prejudicasse. Meus colegas acabaram entendendo. Hoje em dia todo mundo é ecologista, não é? Naquela época era quase um ET (risos).

\section{Acha que a conscientização hoje em dia melhorou?}

A conscientização está boa, só a militância é que não está. As pessoas estão muito passivas. Estão aceitando as coisas. Mas tem algumas exceções. Hoje em dia ninguém vai cortar uma árvore sem que alguém se levante e proteste.

\section{E a quadruplicação da antiga Riocell (atual Celulose Rio-grandense)?"}

Isso eu vou combater até a morte. Estamos tentando barrá-la. Entramos com processo contra isso. Estou esperando a ocasião para entrar de sola contra a quadruplicação, porque eu tenho dados concretos. ${ }^{5}$ É despejada uma tonelada diária de sal no Guaíba.

\footnotetext{
${ }^{3}$ Lewgoy se referiu a Limites do crescimento, obra publicada pela primeira vez em 1972, pelo Clube de Roma. O Clube de Roma surgiu como uma associação de profissionais dos ramos da diplomacia e da indústria, da sociedade civil e da academia, reunida pela primeira vez na capital italiana em 1968, a convite do industrial italiano Aurelio Peccei e do cientista escocês Alexander King, para discutir o dilema de prevalecer o pensamento de curto prazo nos assuntos internacionais e, em particular, as preocupações sobre o consumo de recursos limitados em um mundo cada vez mais interdependente. O Clube permanece em atividade atualmente (The Club of Rome, s.d.).

${ }^{4}$ Referi-me à quadruplicação da capacidade de produção da fábrica, a mesma que já mencionei (Celulose Borregaard), contra a qual vários setores da sociedade gaúcha se insurgiram, entre 1972 e 1974, por conta da poluição do ar e da água por ela provocada. Na ocasião da entrevista (2014), as obras de quadruplicação estavam em pleno vapor.

${ }^{5}$ A quadruplicação não foi impedida. Em maio de 2015, as obras ficaram prontas e houve o início das atividades da parte ampliada.
} 
Eles ainda usam o cloro para branquear o papel?

Ainda usam o cloro, na forma do dióxido de cloro, que julgam menos poluente, mas poluem a atmosfera com toneladas de clorofórmio. Aquelas lagoas de decantação deles liberam clorofórmio no ar, que vai atingir a zona sul de Porto Alegre, transportado pelos ventos. Infelizmente as estações de monitoramento do ar estão desativadas. Tem trabalhos que mostram que antes da quadruplicação o efluente da fábrica já produzia má formação em peixes. Um professor da UFRGS chamado Malabarba ${ }^{6}$ detectou deformidades em milhares de peixes que estavam próximos do cano de descarga dos efluentes da Riocell.

Temos o Ministério Público, que tem um grande poder. Basta apresentarmos dados para eles, e eles atuam. Mas os representantes da Riocell sempre vinham com o argumento de que eram quantidades ínfimas de poluente; picogramas, mil vezes menos que nanogramas.

Em 1992, o professor Peter Krauss, da Alemanha, coletou água do Guaíba, na saída dos rejeitos da empresa, mas não achou dioxinas.

Pode ser até que ele não tenha achado nada além de quantidades infinitésimas. Acontece que não queremos infinitésimos, nós queremos nível zero de poluentes. Até porque isso é constante, cumulativo. No Rio Grande do Sul, há determinados tipos muito comuns de câncer que estão diretamente relacionados com problemas ambientais.

\section{O tratamento da água adianta para esse tipo de contaminação?}

O método usado no tratamento da água é o clássico, que põe carvão ativado só quando tem florescimento de algas, que provoca um gosto desagradável na água.

\section{Do que mais se orgulha de todos esses anos de lutas?}

Não posso dizer que eu me orgulhe. São recordações boas. Acho que eu não fiz mais do que uma espécie de retribuição, por ter estudado em colégio público (Júlio de Castilhos), em universidade pública (UFRGS). Sou a favor do serviço civil. Quem cursa uma universidade pública não paga praticamente nada pelo curso, a não ser em coisas como livros, por exemplo. Depois de formado, o cidadão monta seu escritório, seu consultório, e pronto. Mas, e o curso pago com o dinheiro dos impostos, não acha que deve alguma coisa? Acho que devia ter o serviço civil, para pelo menos devolver esse curso que ele ganhou com o dinheiro dos impostos. A pessoa se formou numa federal, e acha que está tudo bem. Para mim, não está tudo bem. Você está devendo [à sociedade], não em dinheiro, mas em serviços.

Então o senhor acha que colocou o seu conhecimento como químico, como geneticista, a serviço do público?

Sim, acho que não fiz mais do que a minha obrigação. Não preciso me orgulhar disso, fiz o que tinha de fazer. E gostei de fazer, de modo que a satisfação que eu tive foi recompensa

\footnotetext{
${ }^{6}$ Lewgoy se referiu a Luiz Roberto Malabarba, professor titular do Departamento e do Programa de Pósgraduação em Biologia Animal da UFRGS. Desenvolve pesquisas em taxonomia e biologia comparada de peixes neotropicais. Coordena o projeto "Análise sazonal de frequência de anomalias em peixes do lago Guaíba", que monitora a qualidade ambiental do lago por meio da análise de espécies de peixes que o habitam.
} 
suficiente. Recebi diversos títulos, fui eleito para a Academia Rio-grandense de Química (risos). Ganhei uma placa do Conselho Estadual de Saúde, que também ajudei a constituir, ou seja, tudo isso é para mim recompensa suficiente.

Em qual das lutas acha que mais conseguiu contribuir?

As duas leis dos agrotóxicos. Essas foram as que mais me deram satisfação, por eu ter dado uma contribuição importante.

Nelas, o senhor conseguiu aplicar seus conhecimentos?

Sim, e foi uma vitória, minha e de muitos outros que militaram, como o [engenheiroagrônomo] Sebastião Pinheiro. Até hoje o Sebastião é um lutador incansável.

Eu estava lá, o problema estava lá, e eu tinha condições de trabalhar, então trabalhei. E a UFRGS me permitiu. Eu tinha na verdade dois empregos: um emprego de técnico e outro de professor. Hoje, a aposentadoria me permite pagar o condomínio caro deste edifício onde moro, o supermercado, e ajudar os amigos, de vez em quando (risos).

Queria muito agradecer pela entrevista, foi um privilégio conversar com o senhor.

Imagina, enquanto eu estiver por aqui... estou com 88 anos... Muito obrigado.

\section{REFERÊNCIAS}

AGAPAN.

Programa de luta. (Documento do arquivo privado de Augusto Carneiro, Porto Alegre). 27 abr. 1971.

BELMONTE, Roberto Villar.

O detetive da poluição: a luta de Flávio Lewgoy contra os resíduos tóxicos da modernidade. Blog do Villar. Disponível em: https://villar21. wordpress.com/2010/09/25/o-detetive-dapoluicao. Acesso em: $10 \mathrm{dez}$. 2015. set. 2010.

BRASIL.

Lei n.7.802, de 11 de julho de 1989. Dispõe sobre a pesquisa, a experimentação, a produção, a embalagem e rotulagem, o transporte, o armazenamento, a comercialização, a propaganda comercial, a utilização, a importação, a exportação, o destino final dos resíduos e embalagens, o registro, a classificação, o controle, a inspeção e a fiscalização de agrotóxicos, seus componentes e afins, e dá outras providências. Disponível em: http://www.planalto.gov.br/ ccivil_03/LEIS/L7802.htm. Acesso em: $13 \mathrm{dez}$. 2015. 11 jul. 1989.

LEWGOY, Flávio.

A voz dos cientistas críticos. História, Ciências, Saúde-Manguinhos, v.7, n.2, p.503-508. jul.-out. 2000.
PEREIRA, Elenita Malta.

A ética do convívio ecossustentável: uma biografia de José Lutzenberger. Tese (Doutorado em História) - Universidade Federal do Rio Grande do Sul, Porto Alegre. 2016.

PEREIRA, Elenita Malta.

Meio ambiente e ditadura no Brasil: a luta contra a Celulose Borregaard (1972-75). Revista de História Iberoamericana, v.7, n.2, p.147-66. 2014.

PEREIRA, Elenita Malta.

Da proteção à natureza ao desenvolvimento sustentável: a defesa ambiental no Rio Grande do Sul. Tempos Históricos, v.15, n.2, p.117-153. 2011.

RIO GRANDE DO SUL.

Lei n.7.747, de 22 de dezembro de 1982. Dispõe sobre o controle de agrotóxicos e outros biocidas a nível estadual e dá outras providências.

Disponível em: http://www.al.rs.gov.br/ filerepository/repLegis/arquivos/07.747.pdf. Acesso em: 13 dez. 2015. 22 dez. 1982.

THE CLUB OF ROME.

The Birth of the Club of Rome. Disponível em: http://www.clubofrome.org/about-us/history. Acesso em: 13 dez. 2015. s.d. 


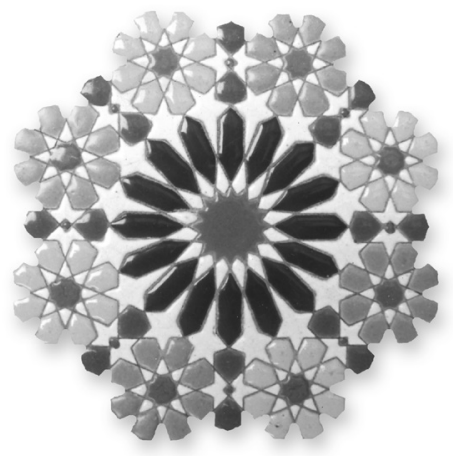

